\title{
Drought assessment and trends analysis from 20th century to 21st century over China
}

\author{
X. L. Yang, L. L. Ren, R. Tong, Y. Liu, X. R. Cheng, S. H. Jiang, and F. Yuan \\ State Key Laboratory of Hydrology-Water Resources and Hydraulic Engineering, Hohai University, \\ Nanjing, China \\ Correspondence to: L. L. Ren (rll@hhu.edu.cn)
}

Received: 12 March 2015 - Accepted: 12 March 2015 - Published: 12 June 2015

\begin{abstract}
Droughts are becoming the most expensive natural disasters in China and have exerted serious impacts on local economic development and ecological environment. The fifth phase of the Coupled Model Intercomparison Project (CMIP5) provides a unique opportunity to assess scientific understanding of climate variability and change over a range of historical and future period. In this study, fine-resolution multimodel climate projections over China are developed based on 7 CMIP5 climate models under RCP8.5 emissions scenarios by means of Bilinear Interpolation and Bias Correction. The results of downscaled CMIP5 models are evaluated over China by comparing the model outputs with the England Reanalysis CRU3.1 from 1951 to 2000. Accordingly, the results from the output of downscaled models are used to calculate the Standardized Precipitation Index (SPI). Time series of SPI has been used to identify drought from 20th century to 21 st century over China. The results show that, most areas of China are projected to become wetter as a consequence of increasing precipitation under RCP8.5 scenarios. Detailed examination shows that the SPI show a slightly increasing trend in the future period for the most parts of China, but drought in Southwest region of China will become the norm in the future RCP8.5 scenarios.
\end{abstract}

\section{Introduction}

The fourth Intergovernmental Panel on Climate Change (IPCC, 2007) assessment released in 2007 reports that a changing climatology of precipitation on regional scales under global warming has begun to affect the frequency, intensity, and duration of drought over the world. With the global warming, droughts are becoming the most expensive natural disasters in China and have exerted serious impacts on local economic development and ecological environment. The fifth phase of the Coupled Model Intercomparison Project (CMIP5) set of experiments (Taylor et al., 2012) provides a unique opportunity to assess scientific understanding of climate variability and change over a range of 20th century and future 21st century under the new greenhouse gas emission scenarios termed "Representative Concentration Pathways" (Moss et al., 2010; Meinshausen et al., 2011). But the CMIP5 models have a typical resolution of a few hundred kilometres, which is too coarse to provide the essential regional-scale variables information required in regional climate change im- pact assessment (Wilby and Wigley, 1997; Wang and Chen, 2014). Statistical downscaling methods are perhaps the most widely used to bridge the gap between GCMs simulations and what is needed in climate impact studies (Storch and Zwiers, 1999).

Based on the quantile-based mapping method (CDF matching) (Panofsky and Brier, 1958), Li et al. (2010) developed the equidistant CDF matching method (EDCDFm), which has been shown to provide downscaling capabilities comparable to other statistical and dynamical methods. The EDCDFm assumes that the difference between the model and observed value during the training period also applies to the future period, which can bias correction of CMIP5 models near surface meteorological fields and is more sensitive to reduced variability in the future projection (Wang and Chen, 2014).

In this study, we use the EDCDFm to downscale the precipitation and temperature of CMIP5 models. Based on the output of downscaled CMIP5 models, the standardized precipitation index (SPI) was calculated to analyze the future 


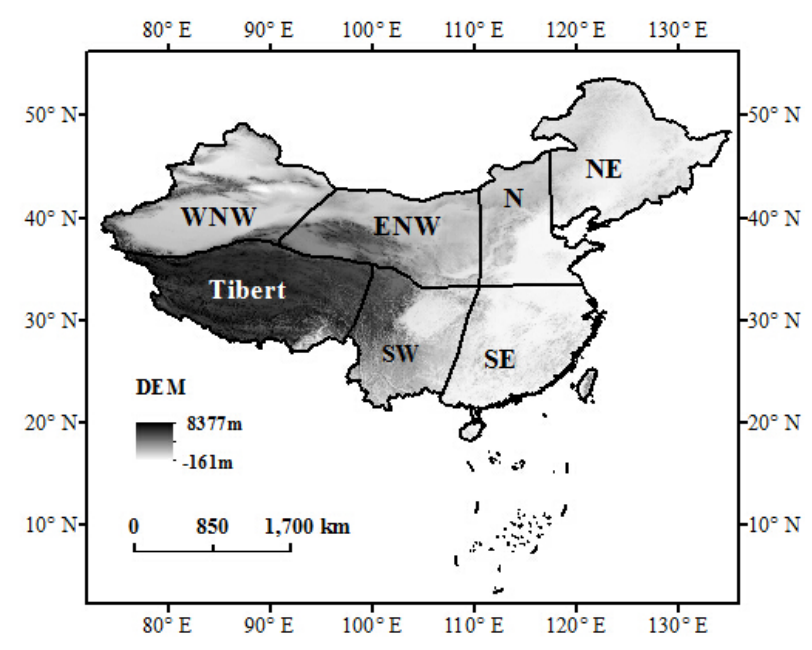

Figure 1. The separate regions within China: Northeast China, North China, Eastern Northwest China, Western Northwest China, Southwest China, Southeast China, and Tibet plateau are marked by NE, N, ENW, WNW, SW, SE, and Tibet respectively.

trend of drought over China. The data used are introduced in Sect. 2. Section 3 describes the methods used in this study. Section 4 shows the performances of the statistical downscaled models' simulations over China. Section 5 shows the results of the projected change in drought by SPI. Section 6 shows the conclusions.

\section{Study area and data sources}

China has a complicated terrain, in which climate varies greatly from region to region. In this research, the whole territory of China was subdivided in seven regions (Fig. 1): Northeast China (NE), Northern China (N), Southeast China (SE), Eastern Northwest China (ENW), Southwest China (SW), Western Northwest China (WNW), and Tibet plateau (Tibet).

Monthly surface air temperature and precipitation output databases from 7 CMIP5 models are selected for the climate change projections in China under the RCP8.5 scenario. The RCP8.5 scenario assumes high population growth and high energy demand without climate change policies. Table 1 gives an overview of the associated institution, the resolution of the atmosphere, and the atmospheric model component of those CMIP5 models. The observations used in this study are gridded monthly temperature and precipitation data prepared by the Climatic Research Unit (CRU) time-series 3.1 dataset (www.cru.uea.ac.uk/cru/data/hrg/) from the University of East Anglia for the global land surface at $0.5^{\circ} \times 0.5^{\circ}$ resolution for the period 1950-2000 (New et al., 2002).

\section{Methodology}

\subsection{The equidistant CDF matching method}

The EDCDFm method was developed by Li et al. (2010), which has been shown to provide downscaling capabilities comparable to other statistical and dynamical methods ( $\mathrm{Li}$ et al., 2010; Wang and Chen, 2014). The EDCDFm is based on the quantile-based mapping method (CDF matching, CDFm hereafter) (Panofsky and Brier, 1958) maps the distribution of monthly general circulation models variables (precipitation and temperature) onto that of gridded observed data with Eq. (1). The EDCDFm assumes that the difference between the model and observed value during the training period also applies to the future period, which means the adjustment function of the entire distribution matches that of the observations for the training period remains the same. For that reason, the difference between the CDFs for the future and historic periods is also taken into account (Eq. 2).

$$
\begin{aligned}
\tilde{x}_{\mathrm{m}-\mathrm{p}} & =F_{\mathrm{o}-\mathrm{c}}^{-1}\left(F_{\mathrm{m}-\mathrm{c}}\left(x_{\mathrm{m}-\mathrm{p}}\right)\right) . \\
\tilde{x}_{\mathrm{m}-\mathrm{p}} & =x_{\mathrm{m}-\mathrm{p}}+F_{\mathrm{o}-\mathrm{c}}^{-1}\left(F_{\mathrm{m}-\mathrm{p}}\left(x_{\mathrm{m}-\mathrm{p}}\right)\right) \\
& -F_{\mathrm{m}-\mathrm{c}}^{-1}\left(F_{\mathrm{m}-\mathrm{p}}\left(x_{\mathrm{m}-\mathrm{p}}\right)\right),
\end{aligned}
$$

where $F$ is the CDF of either the observations (o) or model $(\mathrm{m})$ for a historic training period or current climate (c) or future projection period (p).

The more detail information about this method can be found in reference of $\mathrm{Li}$ et al. (2010). In this study, we applied the equidistant $\mathrm{CDF}$ matching method (EDCDFm) to downscaled the 7 CMIP5 models to $1^{\circ} \times 1^{\circ}$ spatial resolution.

\subsection{The standardized precipitation index (SPI)}

The SPI was proposed by McKee et al. (1993), which quantifying precipitation deficit for multiple time scales and identifying dry and wet events and their severity (Moreira et al., 2006). The SPI is a meteorological index, which is solid theoretical development, robustness, and versatility in drought analyses (Redmond, 2002). The SPI allows analyzing drought impacts at different temporal scales identify different drought types since particular systems and regions can respond to drought conditions at very different time scales. In this study, the downscaled CMIP5 models output are used to calculate the SPI at 12 months' time scales with $1^{\circ} \times 1^{\circ}$ spatial resolution.

\subsection{The assessment methods for model performance}

The validation statistical indices of Root Mean Square Error (RMSE) and Mean Absolute Error (MAE) were employed to evaluate downscaled and original CMIP5 models performance based on the CRU data series both in terms of temporal distribution and amount. The formula for RMSE and 
Table 1. Information of 8 global coupled climate models.

\begin{tabular}{lllr}
\hline Model name & Country & Modeling center (or group) & Resolution (lat $\times$ lon) \\
\hline bcc-csm1-1 & China & $\begin{array}{l}\text { Beijing Climate Center, China Meteorological Administration, } \\
\text { China }\end{array}$ & $2.8^{\circ} \times 2.8^{\circ}$ \\
CanESM2 & Canada & Canadian Centre for Climate Modelling and Analysis & $2.8^{\circ} \times 2.8^{\circ}$ \\
CCSM4 & USA & National Center for Atmospheric Research & $1.25^{\circ} \times 0.9^{\circ}$ \\
CSIRO-Mk3-6-0 & Australia & Common wealth Scientific and Industrial Research & $1.875^{\circ} \times 1.875^{\circ}$ \\
& & Organization in collaboration with Queensland Climate Change & $2.5^{\circ} \times 2^{\circ}$ \\
GISS-E2-R & USA & Centre of Excellence & National Aeronautics and Space Administration \\
MRI-CGCM3 & Japan & Meteorological Research Institute & $1.125^{\circ} \times 1.125^{\circ}$ \\
NorESM1-M & Norway & Norwegian Climate Centre & $2.5^{\circ} \times 1.875^{\circ}$ \\
\hline
\end{tabular}
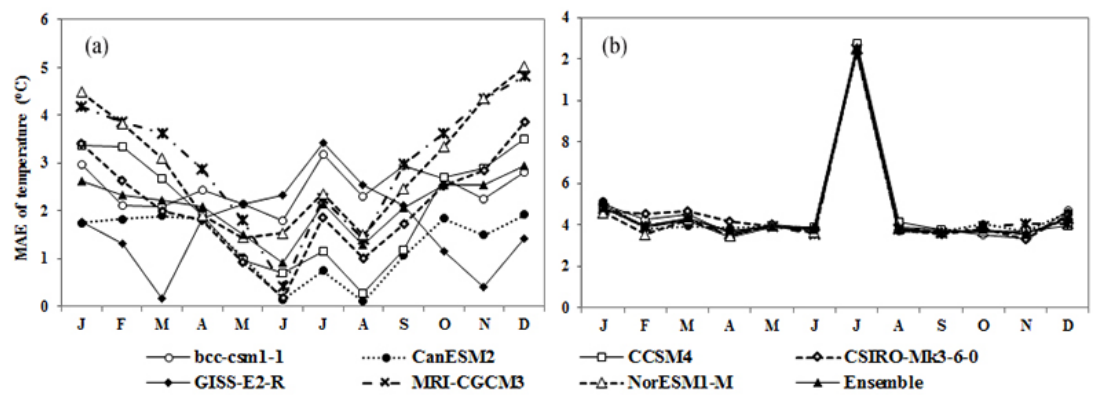

Figure 2. Mean Absolute Error of (a) simulated climatological monthly mean temperature $\left({ }^{\circ} \mathrm{C}\right)$ by original CMIP5 output and (b) downscaled models in China from 1950 to 1999.

MAE are given by Eqs. (3) and (4):

$$
\begin{aligned}
& \text { RMSE }=\sqrt{\frac{1}{n} \sum_{i=1}^{n}\left(K_{\mathrm{Si}}-K_{\mathrm{oi}}\right)^{2} .} \\
& \mathrm{MAE}=\frac{1}{n} \sum_{i=1}^{n}\left|K_{\mathrm{si}}-K_{\mathrm{oi}}\right| .
\end{aligned}
$$

where, $K_{\mathrm{si}}$ and $K_{\mathrm{oi}}$ are the model estimate and the observed value, respectively.

\section{Results and discussion}

\subsection{Model bias}

Table 2 shows the RMSE between the simulated and observed monthly mean precipitation and temperature for each model in China. The RMSE of precipitation simulated by original 7 CMIP5 models are greater than $30 \mathrm{~mm} \mathrm{~m}^{-1}$ for four models (bcc-csm1-1, CCSM4, GISS-E2-R, and NorESM1-M), $20 \mathrm{~mm} \mathrm{~m}^{-1}$ for CanESM2 and CSIRO-Mk36-0 model, and $14 \mathrm{~mm} \mathrm{~m}^{-1}$ for MRI-CGCM3 model, respectively. The RMSE for temperature are range from 1.83 to $3.43^{\circ} \mathrm{C}$. This indicates that most models could accurately recreate the observed climatology for temperature and could not well recreate the precipitation in China. Through the EDCDFm downscaling processes, the monthly temperature
Table 2. The value of RMSE for precipitation and temperature with observation data from 1950 to 2012.

\begin{tabular}{lrrrr}
\hline \multirow{2}{*}{ RMSE } & \multicolumn{2}{c}{ Temperature $\left({ }^{\circ} \mathrm{C}\right)$} & \multicolumn{2}{c}{ Precipitation $(\mathrm{mm})$} \\
\cline { 2 - 5 } & $\begin{array}{r}\text { Original } \\
\text { data }\end{array}$ & $\begin{array}{r}\text { Downscaled } \\
\text { data }\end{array}$ & $\begin{array}{r}\text { Original } \\
\text { data }\end{array}$ & $\begin{array}{r}\text { Downscaled } \\
\text { data }\end{array}$ \\
\hline bcc-csm1-1 & 2.62 & 1.12 & 31.19 & 11.8 \\
CanESM2 & 1.83 & 1.08 & 22.13 & 13.04 \\
CCSM4 & 2.58 & 1.12 & 30.96 & 12.66 \\
CSIRO-Mk3-6-0 & 2.46 & 1.12 & 20.9 & 13.03 \\
GISS-E2-R & 2.13 & 1.16 & 32.94 & 12.15 \\
MRI-CGCM3 & 3.43 & 1.16 & 14.15 & 12.17 \\
NorESM1-M & 3.32 & 1.16 & 40.25 & 12.14 \\
\hline
\end{tabular}

and precipitation all have a slightly lower RMSE than original models. The RMSE of temperature and precipitation decrease to about $1.2^{\circ} \mathrm{C}$ and $13 \mathrm{~mm} \mathrm{~m}^{-1}$, respectively.

Figure 2 shows the biases of temperature between the simulated and observed monthly mean for each model and calendar month. For the seasonal cycle, the simulated temperature in warm seasons is better than that in cool seasons. The MAE of original models in January and July are 2-4 and $0-3{ }^{\circ} \mathrm{C}$, respectively (Fig. 2a). For the original models simulation, the model CanESM2 has the highest skill in reproducing the climatological temperature over China than other 6 models. The MAE of 7 downscaled models desease to 0.3$1.3^{\circ} \mathrm{C}$ throughout the annual cycle (Fig. 2b). Fig.3 shows 


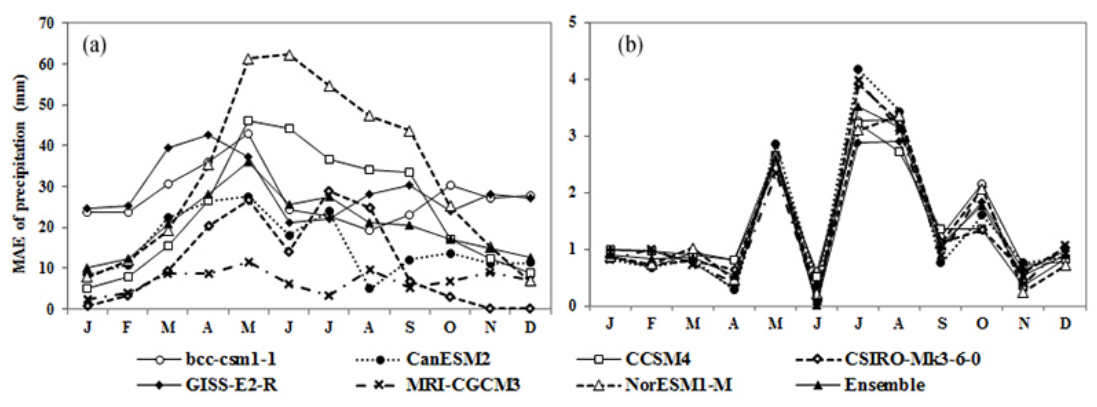

Figure 3. Mean Absolute Error of (a) simulated climatological monthly mean precipitation (mm) by original CMIP5 output and (b) downscaled models in China from 1950 to 1999.
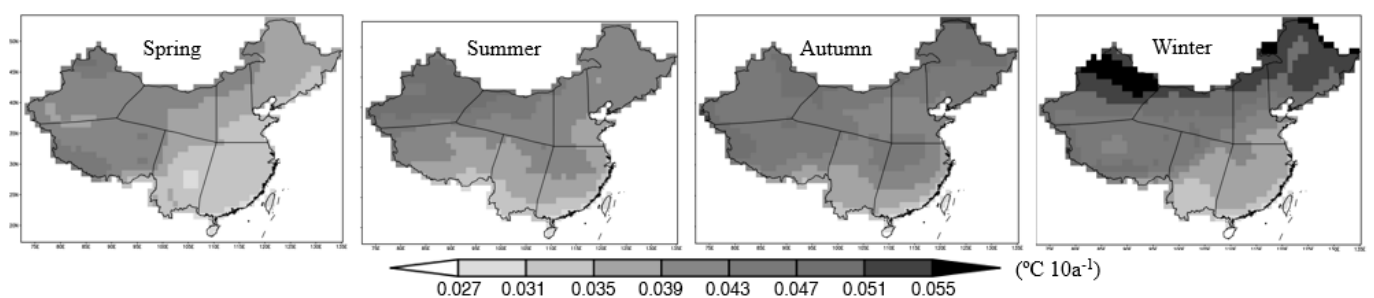

(a)
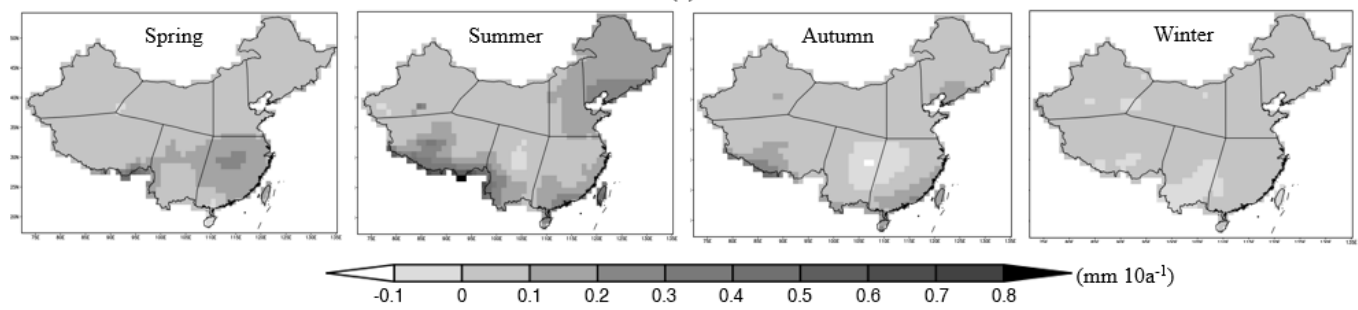

(b)

Figure 4. Geographic distribution of projected changes in the mean monthly temperature (a) and precipitation (b) using the multimodel ensemble mean from 1950 to 2099.

that the biases of precipitation of original CMIP5 models are much larger in summer than in winter, about $26 \mathrm{~mm} \mathrm{~m}^{-1}$ vs. $12 \mathrm{~mm} \mathrm{~m}^{-1}$ in terms of mean (Fig. 3a). Relatively large biases are noticeable in the summer of the year, with the largest MAE being more than $60 \mathrm{~mm} \mathrm{~m}^{-1}$. For the downscaled models, the mean biases decreased to $2.3 \mathrm{~mm} \mathrm{~m}^{-1}$ occur in summer and $0.9 \mathrm{~mm} \mathrm{~m}^{-1}$ in winter (Fig. 3b). The aboved analyses indicate that the EDCDFm has a higher accuracy for the extreme value of temperature and precipitation than that of original models.

\subsection{Projected changes in temperature and precipitation}

To further investigate the spatial pattern of temperature and precipitation changes, Fig. 4 maps the multimodel averaged results in each grid cell. For monthly mean temperature (Fig.4a), the spatial patterns for the slope shows higher temperatures in winter, suggesting a much stronger warming will occur on most parts of China (including NE, N, WNW, ENW, and Tibet). In autumn, a warmer Northwest, Western Northwest, Eastern Northwest, and Tibet plateau are expected in the future under the RCP8.5 scenario. The sub-regions of Southwest and Southeast show a very slightly increasing in all seasons. Overall, the dominant feature in the 21 st century is the widespread temperature increase over China.

The seasonal precipitation of the multimodel ensemble show a different spatial characteristics with temperature (Fig. 4b). The results suggest a slightly increase in precipitation for all seasons cover almost sub-regions of China, except Southwest region. The magnitude of the increase peaks in summertime, with the smallest change in wintertime. In summertime, the downscaled outputs suggest higher precipitation for Northeast, Southeast, and Southwest, particularly for Tibet. Meanwhile, there is a slightly decreasing trend for Southwest region in three seasons except spring time.

\subsection{The trend of drought in China}

The SPI is negative for drought, and positive for wet conditions. As the dry or wet conditions become more severe, the index becomes more negative or positive. Based on the monthly mean precipitation of downscaled CMIP5 models 


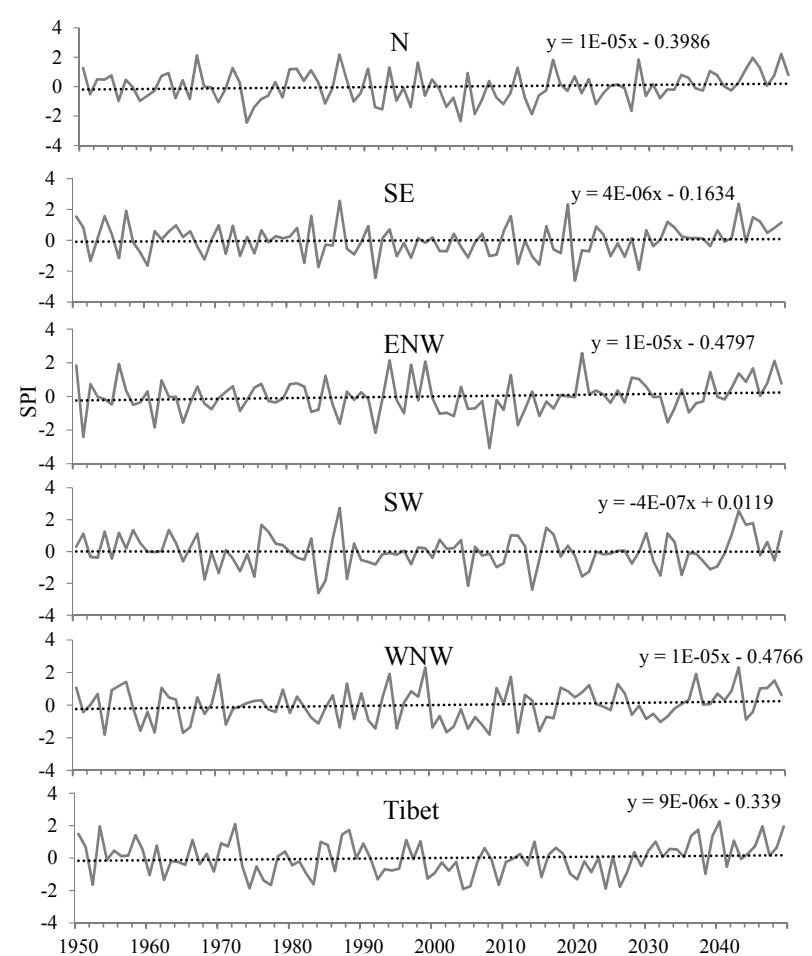

Figure 5. Sub-regions average time series of the SPI in drought from 1950 to 2049 .

output, the SPI with 12 months' time series are calculated in this study. Figure 5 shows the probability distribution of the SPI as calculated across all sub-regions from 1950 to 2049 by ensemble downscaled CMIP5 models output under RCP8.5 emission scenario. It shows that the more recent trend of SPI is similar for the precipitation in each sub-region. The trend detection using SPI indicates statistically lightly negative trend is found in SW region, which means increasing frequency of dry years. In other six regions, there are statistically slightly positive trends (increasing frequency of wet years). The meteorological index SPI is calculated only from the precipitation, which contributes to the trend of SPI in each sub-regions.

\section{Conclusions}

Evaluations of downscaled CMIP5 models performance in China show that the systematic errors in reproducing climatological temperature and precipitation by MAE are 1.08$1.16^{\circ} \mathrm{C}$ and $11.8-13 \mathrm{~mm} \mathrm{~m}^{-1}$, depending on the calendar months and the outcomes from various climate models. For the future period, the results suggest an increase in temperature over the whole country, with the largest increase occurring in winter. There are an increase in precipitation for all seasons cover almost sub-regions of China. Based on the trend analysis of SPI in each sub-region, there will be projected to have a slight increasing drought trend in SW re- gion in the future and an increasing wetter for other six subregions of China in the future.

Acknowledgements. This work was financed by the National Natural Science Foundation of China (Grant no. 41201031, 41323001 and 51479061), Special Basic Research Fund for Methodology in Hydrology under Grant no. 2011IM011000 by Ministry of Sciences and Technology, P. R. China, and 111 Project under Grant no. B08048 by Ministry of Education and State Administration of Foreign Experts Affairs, P. R. China.

\section{References}

IPCC: Climate Change 2007: Synthesis Report, in: Contribution of Working Groups I, II and III to the Fourth Assessment Report of the Intergovernmental Panel on Climate Change, edited by: Core Writing Team, Pachauri, R. K., and Reisinger, A., IPCC, Geneva, Switzerland, 104 pp., 2007.

Li, H. B., Sheffield, J., and Wood, E. F.: Bias correction of monthly precipitation and temperature fields from Intergovernmental Panel on Climate Change AR4 models using equidistant quantile matching, J. Geophys. Res.-Atmos., 115, D10101, doi:10.1029/2009JD012882, 2010.

McKee, T. B., Doesken, N. J., and Kleist, J.: The relationship of drought frequency and duration to time scales, in: Proc. Eight Conf. on Applied Climatology, 17-22 January, Anaheim, CA, Amer. Meteor. Soc., Boston, MA, 179-184, 1993.

Meinshausen, M., Smith, S. J., Calvin, K., Daniel, J. S., Kainuma, M. L. T., Lamarque, J.-F., Matsumoto, K., Montzka, S. A., Raper, S. C. B., Riahi, K., Thomson, A., Velders, G. J. M., and van Vuuren, D. P. P.: The RCP greenhouse gas concentrations and their extensions from 1765 to 2300, Clim. Change, 109, 213 241, 2011.

Moreira, E. E., Paulo, A. A., Pereira, L. S., and Mexia, J. T.: Analysis of SPI drought class transitions using loglinear models, J. Hydrol., 331, 349-359, 2006.

Moss, R. H., Edmonds, J. A., Hibbard, K. A., Manning, M. R., Rose S. K., van Vuuren, D. P., Carter, T. R., Emori, S., Kainuma, M., Kram, T., Meehl, G. A., Mitchell, J. F., Nakicenovic, N., Riahi, K., Smith, S. J., Stouffer, R. J., Thomson, A. M., Weyant, J. P., and Wilbanks, T. J.: The next generation of scenarios for climate change research and assessment, Nature, 463, 747-756, 2010.

New, M., Lister, D., Hulme, M., and Makin, I.: A high-resolution data set of surface climate over global land areas, Clim. Res., 21, $1-25,2002$.

Panofsky, H. A. and Brier, G. W.: Some Application of Statistics to Meteorology, Pa. State Univ., University Park, Pa, USA, 224 pp., 1958.

Redmond, K. T.: The depiction of drought, B. Am. Meteorol. Soc., 83, 1143-1147, 2002.

Storch, H. V. and Zwiers, F. W.: Statistical Analysis in Climate Research, Cambridge University Press, Cambridge, UK, 455 pp. 1999.

Taylor, K. E., Stouffer, R. J., and Meehl, G. A.: A summary of the CMIP5 experimental design, report, World. Clim. Res. Program, Geneva, Switzerland, 1-33, 2009. 
Taylor, K. E., Stouffer, R. J., and Meehl, G. A.: An overview of CMIP5 and the experiment design, B. Am. Meteorol. Soc., 93, 485-498, 2012.

Vicente-Serrano, S. M., Beguería, S., Lorenzo-Lacruz, J., Camarero, J. J., López-Moreno, J. I., Azorin-Molina, C., Revuelto, J., Morán-Tejeda, E., and Sanchez-Lorenzo, A.: Performance of drought indices for ecological, agricultural, and hydrological applications, Earth Interact., 16, 1-27, 2012.

Wang, L. and Chen, W.: A CMIP5 multimodel projection of future temperature, precipitation, and climato logical drought in China, Int. J. Climatol., 34, 2059-2078, 2014.
Wilby, R. L. and Wigley, T. M. L.: Downscaling general circulation model output: a review of methods and limitations, Prog. Phys. Geogr., 21, 530-548, 1997.

Wood, A. W., Leung, L. R., Sridhar, V., and Lettenmaier, D. P.: Hydrologic implications of dynamical and statistical approaches to downscaling climate model outputs, Clim. Change, 62, 189-216, 2004. 